\title{
SUCATA VIRA BRINQUEDO: TRADUÇÃO A PARTIR DE RESTOS
}

\author{
Maria de Fátima Aranha de Queiroz e Melo \\ Universidade Federal de São João del Rei e Universidade Estadual do Rio de Janeiro \\ Mônia Aparecida da Silva \\ Ellen Pinheiro Tenório de Albuquerque \\ Luciana Toledo de Melo Ramos \\ Dylene Elvira da Silva Gonçalves \\ Marcela Herthel de Oliveira \\ Gisele da Consolação Miranda \\ Universidade Federal de São João del Rei, São João del Rei, Brasil
}

\begin{abstract}
RESUMO: Neste artigo, chamamos a atenção para a necessidade de assumirmos a responsabilidade sobre o destino de nosso lixo, propondo para ele uma nova utilização. Tomamos a Teoria Ator-Rede como instrumento teórico metodológico para seguir a ação desenvolvida por uma das equipes da Brinquedoteca da Universidade no que chamamos de Projeto Sucata cujo objetivo tem sido transformar sucata em brinquedo com um grupo de crianças de uma comunidade de baixo poder aquisitivo de uma cidade mineira, tendo os conceitos de tradução e mediação como suportes para a descrição das transformações operadas nas partes envolvidas.
\end{abstract}

PALAVRAS-CHAVE: Brinquedo-sucata; teoria ator-rede; tradução; mediação.

\section{SCRAPS TURN INTO TOYS: \\ TRANSLATIONS MADE FROM RUBBISH}

ABSTRACT: In this article we call attention to the necessity of taking responsibility for the destination of the waste we generate, proposing an alternative use. The Actor-Network Theory was used as a theoretical methodological instrument for the Projeto Sucata (Scrap Project) developed by the staff of the Brinquedoteca da Universidade (University's Toy Library) and whose goal has been to transform waste scraps into toys with the participation of children from a low-income neighborhood of a city in Minas Gerais. Translation and mediation were used as concepts for describing the process of transformation that occurred among all the parts involved.

KEYWORDS: Scrap-toy; actor-network theory; translation; mediation.

\section{O lixo nosso de cada dia}

Alguém parou para pensar sobre a trajetória realizada por uma latinha de ervilhas, desde a sua fabricação, sobre o tempo e a finalidade de seu uso, até que vira "sucata"? Que materiais teriam sido mobilizados para sua feitura? Que necessidades impuseram o seu aparecimento? Por quais razões este objeto faz parte de nossas vidas? Que destino lhe aguarda? Será biodegradável? Quanto tempo levará até que seja absorvido pela natureza? Será passível de re-aproveitamento? A proposta de seguir as transformações que se operam nas etapas desta cadeia de produção, apropriação e difusão de um objeto em particular foi lançada por Callon (citado por Dosse, 2003) na defesa da idéia de que os objetos são inseparáveis do tecido social do qual fazem parte. Para nós, esta idéia fermenta uma reflexão da qual não podemos nos furtar em pleno século $X X I$, uma vez que vivemos num coletivo ${ }^{1} \mathrm{em}$ que, cada vez mais, fabricamos lixo. De diversas ordens, os refugos de uma sociedade de consumo nos impõem classificações variadas para organizar o caos das sobras que produzimos: cestas para latas, para vidros, para papel, para plásticos, para orgânicos. Múltiplas tentativas, enfim, para fazer uma coleta ordenada, tendo em vista uma possível reutilização de produtos tão heterogêneos. Quando não são embalagens, são sobras de materiais que serviram como matéria-prima para a fabricação de algum bem que faz parte de nossas vidas. Diz Bauer (2003) que esta capacidade de produzir objetos é, além da comunicação através de símbolos, uma característica única dos humanos. $\mathrm{Na}$ esteira desta produção de objetos, somos, sem dúvida, a única espécie capaz de produzir lixo em proporções inusitadas. Do lixo mais inocente, o chamado lixo orgânico, que retorna à natureza para torná-la mais fértil, ao lixo radioativo que, se não é letal ao contato humano, pode produzir danos irreversíveis, lidamos com controvérsias das mais inesperadas com relação às decisões que envolvem o destino das nossas sobras.

Aterros sanitários, associações de catadores de lixo, biodigestores, lixo hospitalar, depósito de ferro-velho são alguns dos novos híbridos ${ }^{2}$ que surgiram, nas últimas décadas, nesta rede que tem como um dos nós a questão 
do lixo. Sucata, por exemplo, é um termo que começou a ser usado para designar um tipo específico de sobra, em geral proveniente das peças obtidas do desmonte de automóveis e outras máquinas, mas que se generalizou para outros tipos de material, uma vez que os chamados ferrosvelhos passaram a abrigar uma quantidade e uma variedade mais ampla de objetos aparentemente inúteis. Mudando o ângulo do olhar, a sucata perdeu sua condição de inutilidade e tem virado matéria-prima para o trabalho de artesãos, inventores de engenhocas e artistas plásticos que garimpam, nestas misturas de materialidade e socialidade (Law \& Mol, 1995), inspiração para construir protótipos inéditos. Sucata passou a ser um termo que se generalizou para designar o lixo de diversos tipos e procedências e se difundiu nos meios de comunicação, pois a sua coleta e redistribuição passaram a ser uma atividade lucrativa que possibilitou a fortuna de alguns com a sua conseqüente glamourização.

Didonet (1982) entende o termo sucata com uma conotação diferente daquela que freqüientemente lhe é atribuída. Para o autor, sucata não quer dizer lixo, ferro velho, ou mesmo coisas jogadas fora. A sua idéia sobre a sucata remete a "objetos que já tiveram um determinado uso e que passam a ser matéria prima para ser transformada e adquirir um novo significado" (p. 17).

Para Machado (1999), a sucata é um material que traz a marca da transformação porque, descontextualizada, oportuniza usos incomuns que são sugeridos pelo próprio material, assim como pelo que nós nele projetamos. Há também, na sucata, segundo a autora, uma mensagem psicologicamente construtiva na reutilização daquilo que comumente chamamos de "lixo": a de que podemos lidar construtivamente com os restos, seja da natureza, das atividades humanas, e com o nosso próprio lixo interno, das partes que não nos agradam mais e que precisam ser transformadas.

Weiss (1989) classifica o material sucata em dois grandes grupos: (a) a sucata natural, constituída de elementos da natureza como pedras, folhas, sementes, galhos, areia, terra, entre outros, típicos de cada contexto; (b) a sucata industrializada que integra todo o tipo de material refugado de práticas de transformação da matéria prima, incluindo-se aí os vários tipos de embalagens de plástico, metal, vidro, papel, madeira e pano. É a pesquisa em torno do próprio material que induz às possibilidades de sua transformação/re-significação.

Cunha (1988) dá relevo ao aspecto econômico na utilização da sucata como matéria prima para a confecção de brinquedos, acrescentando o fato de que criar a partir de material descartável é um "desafio à nossa capacidade", "uma proposta de mudança" e um "convite à aventura" (p. 25). Trata-se de uma atitude de reinvenção do mundo a partir de restos considerados, a princípio, inúteis, mas que assumirão novos contornos em função do destino que lhes dermos. A subversão dos usos esperados para os materiais abre um campo inédito para a sucata como matéria prima, gerando novos e imprevistos significados. Um espírito lúdico, mais que tudo, seria a mola propulsora deste processo, na tentativa de escapar de uma reprodução estereotipada, calcada num receituário prévio do como fazer.

Com estas concepções da sucata, retoma-se o sentido ecológico deste material, pois estaremos, a todo o momento, atentos a um meio ambiente em transformação, rico de possibilidades, direcionando nosso olhar para objetos e materiais que eram antes insignificantes e inúteis. Educar o olhar, tornar hábeis os movimentos, coordenar as ações, atribuir novos significados são partes integrantes no processo de construção do brinquedo-sucata.

Benjamin (1984) já chamava a atenção para as múltiplas possibilidades que a imaginação infantil encontra nos restos dos afazeres do mundo adulto. Onde só conseguimos ver sobras imprestáveis, as crianças conseguem vislumbrar um mundo de formas, texturas e cores que vão sugerindo novas e surpreendentes composições com as quais se deleitam nos seus jogos simbólicos. Pedaços de madeira viram carrinhos; retalhos de pano podem vestir bonecas; galhos viram estilingues, arcos, flechas, nas brincadeiras de índio e cowboy; comida de boneca pode ser feita de folhas e flores caídas do jardim, bem arrumadas em pratinhos aproveitados de tampas plásticas. Segundo Benjamin, na mesma obra, a própria história do brinquedo teria encontrado seu nascedouro nas oficinas dos artesãos, uma vez que, em tamanho miniaturizado, o brinquedo seria, por excelência, um produto confeccionado a partir de sobras. Só no século XIX, os brinquedos encontrariam a ampliação de suas formas e tamanhos, perdendo a sua condição de miniatura e tomando caminhos próprios em sua fabricação e comercialização.

\section{O brinquedo-sucata na rede: por uma Sociologia da Tradução}

Utilizaremos, para descrever o trabalho com a sucata, a Teoria Ator-Rede (TAR), também chamada de Sociologia da Tradução, por entendermos que este referencial teórico metodológico nos dará a flexibilidade necessária para abordar o tema em questão. Diz Latour (2003) que podemos descrever uma rede com qualquer teoria social, mas a Teoria Ator-Rede nos possibilita descrever qualquer coisa, não necessariamente uma rede. Podemos entendêla mais como um instrumento do que como um produto, sendo "mais um pincel do que a paisagem que ele pinta" (p. 3). Serres (1999) defende uma lógica em redes, pois a perspectiva linear limita muito a compreensão dos fenômenos: coisas que uma linha faz parecerem muito distantes podem ser vistas como próximas se as observarmos segundo a sua conectabilidade, pois o tempo e o espaço podem dobrar-se, enriquecendo as nossas descrições, ao 
invés de tomá-las dentro de uma perspectiva estática. A lógica das redes é uma lógica das traduções, pois se opera em cadeias nas quais vários tipos de materiais heterogêneos e díspares vão se conectando para produzir mesclas inéditas, num movimento incessante e inesperado que inclui simetricamente o engenho humano e a durabilidade da matéria, numa parceria construída ao longo de toda uma história que associa os humanos aos materiais que fazem durar as suas ações no tempo. O conceito de tradução nos oferece um eixo de análise para o entendimento dos fenômenos estudados pelas humanas ciências ${ }^{3}$, assumindo uma posição de centralidade dentro da abordagem teórica da TAR, pois conjuga dois movimentos: o de associação (pelas conexões estabelecidas) e o da ação (através das cadeias que vão produzindo a diferença). Trata-se de um processo que ocorre em fluxos que deslocam interesses, objetivos, enunciados, imagens, em que os elementos vão passando de um lugar a outro, de uma rede a outra, tornando-se muito diversos do que eram no início. As cadeias de tradução pelas quais passam os não humanos, ${ }^{4}$ assim como os humanos, nos mostram como, a cada etapa, perdem-se algumas propriedades para ganhar outras, dentro das condições oferecidas em determinadas redes. A tradução tornou-se um conceito amplo que significa, além da passagem de uma linguagem a outra, o deslocamento de um lugar a outro, um desvio de rota, uma invenção, uma mediação, a criação de um elo que não existia antes, dando espaço para a emergência da novidade e enfatizando a atividade de fabricação e circulação de enunciados. Devido a esse transporte, a tradução implica, simultaneamente, em similaridade e em diferença: algo se mantém e, ao mesmo tempo, algo se desloca e se modifica. Por essa razão, Law (1997) diz que toda tradução também é traição, pois nunca haverá uma representação definitiva da parte da realidade que se deseja capturar. A busca de constância apontará para as semelhanças, para a manutenção de um padrão, mas o próprio movimento de tradução implicará em deslocamentos e modificações. É nessa tensão que trabalha a Teoria Ator-Rede. Quando as traduções se operam através da cadeia de mediadores por que passam os elementos, são as conexões das redes que vão oportunizando o trabalho da diferença.

$\mathrm{O}$ brinquedo, a sucata e o brinquedo-sucata como resultante da associação dos dois primeiros cabem bem no espírito das descrições feitas pela TAR em que podemos seguir as similaridades e diferenças que vão se desdobrando nas cadeias de tradução. Eles são caracterizados pela manutenção e pela mudança nas suas expressões, pois podemos constatar as inúmeras versões por que passam estes elementos segundo as condições locais em que estão imersos. Há um padrão que se mantém minimamente estável e que nos permite reconhecer o objeto, assim como há mudanças que vão ocorrendo nos ambientes em que vai sendo encontrado, assumindo novas feições, de acordo com a cultura, com os grupos de brincantes, com a geografia e as condições materiais do lugar, dependendo das conexões que vai estabelecendo na rede. Ao passar de mão em mão, o objeto é traduzido e passa a ter uma autoria coletiva, indo de um enunciado local a outro de implicações gerais e vice-versa.

O conceito de mediação, tanto quanto o conceito de tradução, têm ampliadas suas possibilidades de alcance, abandonando o constrangimento de uma aplicação restrita apenas ao humano. Em Latour (1994b), a mediação remete à idéia de meio de onde deve partir toda a análise sociológica, pois se trata de um ponto médio em que a ação de localizar e globalizar se encontra como um operador que concentra e dispersa as interações, dando simetria a humanos e não humanos, na emergência da novidade, da criação. Mediar é interferir, é fazer a diferença na produção de um efeito e, além disso, não se trata de uma ação exclusiva dos humanos. Nenhum homem pode ser tão capaz e poderoso na produção de qualquer coisa sem entrar em negociação com elementos não humanos. Alguma coisa acontece que não é o simples transporte de força para a matéria, nem a simples projeção de uma idéia sobre os materiais. Ao agir, estamos sempre sujeitos à surpresa de nossa ação, sempre somos ultrapassados por aquilo que fabricamos, pois estaremos dividindo esta ação com outros actantes. ${ }^{5}$ Qualquer ceramista, qualquer arquiteto, engenheiro, ou marionetista, usando os exemplos oferecidos por Latour (2002a), reconhece que as coisas com as quais trabalha oferecem recalcitrâncias, ${ }^{6}$ impõem estratégias, não são tão facilmente domináveis. Há uma conjunção de fatores que facilitam ou dificultam este domínio e a ação nunca se dá linearmente numa relação de causa e efeito, mas sempre em rede, pela associação inesperada de vários actantes.

Na hipótese de Latour (1994a), o pensamento instaurado pela modernidade designa dois conjuntos de práticas diferentes que precisam estar apartadas uma da outra para terem alguma eficácia:

1. As práticas de tradução, responsáveis pelas misturas que fazem surgir os híbridos de natureza e cultura.

2. As práticas de purificação que negam as misturas efetuadas entre humanos e não humanos, operadas pelo conjunto de práticas anteriormente mencionado e, portanto, só fazem sentido em função deste.

As práticas de tradução das quais estivemos falando acima são inevitáveis, se seguimos a abordagem da TAR, pois constituem o movimento da própria vida que surge como resultado do acaso, da mutação e da desordem (Latour \& Woolgar, 1997), sendo esta relação ordem/desordem já bastante familiar aos biólogos.

As práticas de purificação, uma fabricação das ciências modernas, aparecem, entretanto, como uma necessidade 
de negar as primeiras, transformando a tarefa científica num paradoxo impossível de resolver. O iluminismo atribuiu ao humano a condição de criador, operando-se uma separação estratégica deste com os elementos da natureza, a partir de uma série de cisões que ocorreram nesta esteira de purificações, na tentativa de construir um conhecimento verdadeiro. Para tanto, o entendimento da realidade passou a se dar dentro de uma lógica bi-polar, principalmente no que se refere a um pólo do sujeito que conhece e a um pólo de um objeto que é conhecido. Foi dando flexibilidade ao primeiro e fixidez ao segundo que se consolidou a hegemonia do pensamento ocidental.

O lixo nosso de cada dia é uma invenção tipicamente moderna, pois surge como resultado destas duas práticas. São mesclas de natureza e cultura, produzidas incessantemente, pelas quais não queremos nos responsabilizar, refugando-as, ocultando-as, execrando-as e, num movimento de ascetismo constante, tornando-as estranhas e indesejáveis ao nosso convívio.

\section{O Projeto Sucata: seguindo traduções e mediações}

É a partir destas idéias que a sucata tem se constituído para nós como a matéria-prima que instiga à fabricação de brinquedos. A proposta do Projeto Sucata, como tem sido chamado o nosso trabalho, surgiu como uma das atividades realizadas pela equipe da Brinquedoteca da Universidade Federal de São João Del Rei e, fundamentalmente, da necessidade de oferecer opções lúdicas sem custo a uma clientela de baixo poder aquisitivo num país extremamente pobre de recursos dirigidos aos setores populares, embora com uma enorme capacidade para produzir lixo. Nossos trabalhos tiveram início no ano de 2004, se estenderam ao longo dos anos de 2005 e 2006, tendo a perspectiva de continuarem ao longo do ano de 2007 , em função da aceitação verificada na Comunidade São Dimas, que abraçou a idéia, contando com o apoio da Pastoral da Criança cuja sede nos foi cedida para a realização das oficinas.

A metodologia utilizada neste projeto constou de várias etapas que ocorreram de maneira seqüencial ou simultânea. Nosso primeiro passo foi coletar sucata e por ela nos deixar provocar, buscando formas para efetivar a sua transformação em brinquedos. A sucata era limpa e selecionada, passando por várias formas de classificação: por tipo de material, por tamanho, por forma, por cor. Foram montados dois sucatários ${ }^{7}$, ficando um na Brinquedoteca e outro nas dependências da Pastoral da Criança, na comunidade do bairro São Dimas. Adotamos a orientação de Machado (1999) no sentido de montar os sucatários de forma que fossem atraentes ao olhar e ao tato, motivando as crianças a realizarem o manuseio e a transformação dos materiais.
Das oficinas, participaram uma média de trinta crianças com idades entre 2 e 13 anos, agrupadas em três encontros semanais de aproximadamente duas horas. As três duplas de estagiárias buscaram agir no sentido da sugestão e não da imposição, no que diz respeito ao processo de construção do brinquedo-sucata. Nossa intenção inicial era oferecer uma alternativa barata e acessível ao brinquedo industrializado, usando a sucata como material para a construção de brinquedos. Entretanto, um dado que nos causou surpresa foi o fato de que o processo de transformação da sucata em brinquedo interessou mais as crianças do que a possibilidade de serem possuidoras de um brinquedo bem acabado e atraente. As crianças encontravam divertimento nessa passagem, no manusear os materiais, buscando com os conectores novas composições para as peças disponíveis. Pautaram-se, na maioria das vezes, pelo desejo de ter um resultado imediato, ao invés de investirem nas etapas de confecção de um brinquedo mais elaborado. "Uma coisa"8 era como comumente denominavam as produções que ainda não tinham uma aparência definida para que esta se revelasse aos poucos com o passar do tempo. Este fato ora se revelou numa opção consciente, ora se deu como fruto de uma dificuldade para realizar uma produção passo a passo. Alguns protótipos, embora não todos, tiveram a adesão dos grupos como uma opção para a construção. Um dos protótipos aceitos foi o porquinho fabricado a partir da técnica de papietagem, utilizando uma composição de bolas de encher que eram recobertas com pedaços de papel e cola e, posteriormente, pintadas, sendo suas patas feitas com as células de caixas de ovo. Além do cofre de porquinho, outras traduções desta mesma técnica surgiram: mais porquinhos, um peixe, uma nega maluca... Caixas grandes viravam escolas, oficinas para conserto de carros, lanchonetes. Caixas pequenas viravam blocos de montagem para elementos maiores.

Um outro dado relevante no projeto é que as manifestações culturais, especialmente as religiosas, vivenciadas pela comunidade, permearam recorrentemente a temática e a dinâmica da construção dos brinquedos-sucata. Em função do calendário das festas, as crianças costumavam elaborar as experiências que the causavam profunda impressão, reproduzindo ludicamente as práticas do seu grupo de pertença. Enfeites e presentes relativos a datas festivas, imagens de santos sobre andores improvisados em procissões de mentirinha foram elementos buscados pelo grupo durante as oficinas. Uma garrafinha de iogurte, na sua nova versão mais sinuosa, já não era a mesma ao virar o corpo da Virgem Maria. Da mesma forma, a Nossa Senhora das procissões encontrou uma versão inédita na sucata transformada. Nada ficou como antes na medida em que, pelas cadeias de tradução, num fluxo constante de movimentos, pudemos observar novas conexões sendo feitas entre idéias, materiais e oportunidades. Novos hí- 
bridos surgiram a partir destes movimentos, mesclando, num só evento, outros que antes não apareciam associados.

Uma controvérsia que pudemos seguir durante a construção do brinquedo-sucata foi a da autoria e do plágio nos produtos obtidos. Se uma criança conseguia realizar o seu protótipo com sucesso, ela era rapidamente seguida por outras que também desejavam obter um resultado semelhante. Não raro, esta ação gerava protestos do pioneiro com a queixa de que havia sido copiado. Os plagiadores, entretanto, defendiam-se com o argumento de que os seus exemplares tinham marcas que os diferenciavam do produto original, como se fossem traduções de um modelo, cada um com seus pequenos desvios e soluções particulares. A idéia da autoria como posse única e inequívoca, na perspectiva da TAR, passa a ser relativizada uma vez que é a partir das necessidades práticas de um coletivo que a tessitura de determinados programas de ação vai se forjando. Como cristalizar a idéia de autoria dentro de uma perspectiva em redes? Como impedir o movimento de transformação da sucata em traduções tão particulares e tão variadas? A criação de alguma coisa é sempre um projeto transpassado por muitas entidades, ${ }^{9}$ sendo o crédito deste surgimento sempre compartilhado entre vários agentes.

Nas redes de atores, nunca estaremos confrontados com a ação de um. Coisas, pessoas, políticas, instituições estarão combinadas na produção de efeitos que se cruzam. Os objetos e as técnicas utilizadas para sua criação estarão inextrincavelmente enlaçados com os coletivos que os forjaram. Sociedades e técnicas, longe de se oporem, fazem parte de um mesmo fenômeno, emergindo juntas para permitir novas maneiras de resolver as questões práticas da vida comum. Por isso, Latour (2001) utiliza o termo sociotécnicas para qualificar as estratégias de mediar, ou seja, de interferir para a obtenção de um determinado fim.

Latour (2001) atribui quatro significados à mediação sociotécnica, todos forjados a partir da idéia das traduções que se operam nas redes: (a) o da interferência ou do programa de ação; (b) o da composição; (c) o do obscurecimento reversível; e (d) o da delegação. Em maior ou menor grau, estes significados de mediação aparecem em todas as ações que realizamos como parte de nossa tarefa de sobrevivência nos coletivos.

Na transformação da sucata em brinquedo, podemos observar esses quatro significados de mediação ocorrendo:

Para atingir um fim, é necessário ter um programa de ação, ou seja, materiais, estratégias, circunstâncias, que nos permitam fazer a diferença entre um ponto zero e o atingimento do objetivo que buscamos. Esse programa de ação é o que, nas ações que desempenhamos, interfere na consecução de nossas metas. O trabalho de transformação da sucata nos impõe desafios e perplexidades. A busca de protótipos que nos servissem como inspiração e a testagem de elementos conectores para diferentes texturas foram algumas de nossas preocupações, pois cada material nos impunha um tipo de desafio novo para que pudéssemos testar a eficácia de nossas estratégias. Para a madeira, pregos, martelo e cola; para o pano, agulha e linha; para o papel, cola plástica e grampos. A pistola de cola quente, assim como as tintas, foram elementos privilegiados e largamente utilizados, pois promoviam efeitos quase imediatos sem que fosse imposta uma longa espera para a obtenção de um resultado final.

A mediação sociotécnica, vista sob o ângulo da composição, encontrou, no trabalho com a sucata, fartos elementos de verificação, pois este trabalho foi pautado essencialmente pela possibilidade infindável de fazer combinações inéditas e insuspeitadas. De uma maneira geral, o trabalho de fazer a sucata virar um brinquedo teve origem em alguns movimentos já previstos por Weiss (1989): (a) a criança chega com o desejo de construir um brinquedo específico e procura determinado tipo de material nem sempre disponível que lhe permita tal empreitada; (b) os materiais disponíveis se impõem ao projeto da criança, sugerindo com suas formas, cores e texturas um tipo de brinquedo a ser produzido; (c) o trabalho com a analogia de formas vai se processando numa combinação em que novas relações vão se criando para a produção de algo que não estava previsto no início. Neste caso, o processo de criação individual ou grupal deixa margem para a surpresa co-optada, na relação criança-material, assim como na relação criança-criança e mesmo na relação criançaadulto.

O terceiro significado para a mediação, o do obscurecimento reversível, tem uma compreensão particularmente instigante no caso da sucata. Um objeto cujo uso é dado como certo e inequívoco em nossos coletivos passa despercebido e tem todas as suas etapas de fabricação obscurecidas por sua obviedade, até que uma nova controvérsia se instala em torno de sua utilização. É assim que legiões de agentes passam a ser mobilizados quando algo não funciona da forma prevista, quando, por exemplo, uma máquina quebra, quando falta energia elétrica, quando metroviários entram em greve, quando uma nova idéia surge no cenário das idéias já consolidadas, abrindo o que dantes estava lacrado como uma caixa-preta, ${ }^{10}$ dando ensejo a uma re-abertura de questões que estavam assentadas em várias camadas de ações que foram se sobrepondo, que foram tomadas como consensuais e aceitas por todos, ao longo do tempo. O trabalho de transformação da sucata em brinquedo propõe-se a re-abrir a discussão do que fazer com nosso lixo, de verificar a sua trajetória enquanto uma fabricação, ao mesmo tempo em que lança o desafio de criar objetos de suporte para uma atividade que se tem tomado como uma matriz vital e necessária para a sobrevivência: o brincar. 
O quarto significado da mediação sociotécnica é o da delegação. Delegamos às coisas ações que carregam mensagens, uma vez que se perpetuam plasmadas nos materiais. Diz Latour (1996) que uma boa parte da moralidade de nossas sociedades se deve a essas mensagens que as coisas carregam para nos lembrar, ou melhor, para não nos deixar esquecer de certas advertências. Assim, por exemplo, um quebra-molas, instalado no campus de uma universidade, nos avisa da necessidade de não ultrapassar determinada velocidade. $O$ perigo de atropelamento pela impetuosidade de alguns motoristas pode ser evitado com a instalação destes guardas de concreto que deslocam uma atitude de cuidado com o outro para uma atitude de preservar a suspensão de nosso próprio veículo. Da mesma forma, o cinto de segurança nos protege de nossa imprudência ao dirigir, o despertador nos lembra da hora do compromisso assumido no dia seguinte. E a sucata nos lembra que precisamos encontrar formas diferentes de lidar com o destino dos objetos que produzimos, obrigando-nos a refazer, no sentido contrário, o caminho percorrido pelo material tido como inútil. Trata-se de uma consciência ambiental que precisa ser desenvolvida e de uma responsabilidade que deve ser assumida com relação às nossas sobras. Uma garrafa PET pode ser jogada nas margens de um rio ou num bueiro, provocando um assoreamento desnecessário ou pode encontrar, na sua transformação, um destino antes não previsto. Pode juntar-se a muitas outras garrafas PET para virar uma enorme balsa, ${ }^{11}$ pode encontrar nova tradução num carrinho de corrida, numa árvore de natal, numa cabeça de fantoche; pode ser fatiada infinitamente até virar cerda de vassoura e mais um número surpreendente de outras coisas, basta que sigamos as ações desenvolvidas sobre o material à luz dos quatro significados da mediação sociotécnica. O papel é outra sobra privilegiada que já tem encontrado destinos mais nobres do que a fornalha. A reciclagem de papel pode evitar uma boa parcela de desmatamento, embora ainda estejamos distantes de uma política eficaz para preservar nossas florestas. A madeira é um material em extinção que se torna mais raro a cada dia, fato que gera opções como o $\mathrm{MDF}^{12} \mathrm{e}$ os compensados, provavelmente algumas das traduções que a madeira encontrará neste século.

A utilização parcimoniosa do material (sucata e conectores) assim como a limpeza do recinto, ao final das oficinas, não foram dados iniciais, no nosso projeto. Ao contrário, foi uma conquista gradual dos grupos, dando sinais de uma crescente consciência ambiental por parte dos envolvidos. Do desperdício e da desordem dos encontros iniciais, foram-se criando estratégias para organizar e poupar os materiais nos encontros posteriores. $\mathrm{O}$ envolvimento das crianças foi paulatinamente construído, inclusive com a sua adesão na coleta de material dentro da própria comunidade.

\section{Algumas considerações para um desfecho provisório}

Algumas considerações nos cabem fazer para descrever as aprendizagens realizadas durante este projeto. A primeira delas refere-se à metodologia por nós utilizada, uma vez que esta escapou de uma visão apriorista do que seria feito durante as oficinas. Procurou-se evitar uma atitude pedagogizante que costuma ser a tônica das ações que envolvem o trabalho com crianças, deixando que $o$ ritmo das oficinas corresse por conta da temática e da dinâmica trazida pelos participantes, mesmo com a introdução dos protótipos que podiam ou não ser adotados em suas diferentes versões.

Buscando coerência com o referencial adotado, consideramos que o processo de ensinar/aprender/conhecer/ construir é uma empreitada de riscos. Na proposta de construir brinquedos com sucata, todos corríamos riscos na realização dessa passagem, pois ninguém detinha a priori um resultado final ao qual necessariamente chegar. Cada pessoa, a partir de sua história e das redes que a compunham, tinha um estilo único de realizar esta tarefa que estava sempre passível de modificações em função das novas conexões que iam ocorrendo.

Olhar para as recalcitrâncias dos materiais no Projeto Sucata, mais que uma oportunidade de fazer aprendizagens, contribuiu para a construção de uma estratégia de sobrevivência, num mundo em mudança. Uma atitude diferente pôde surgir como resultado deste trabalho, tanto por parte do grupo de crianças como por parte do grupo responsável pelo desenvolvimento do projeto, uma vez que nenhum dos envolvidos foi o mesmo depois desta passagem. Conquistamos um olhar e um fazer diferentes em relação às nossas sobras, pois passamos a ser capazes de nos deixar afetar pela possibilidade de transformar a sucata em outra coisa, olhamos os nossos restos de outra maneira, buscamos usos incomuns em materiais que antes continham um único e inevitável destino, ficamos mais interessados na questão do lixo e podemos dizer que realizamos aprendizagens preciosas porque nos deixamos provocar por novas possibilidades de criar. Se há uma distância entre o novo repertório de ações dos envolvidos e aquele que foi o ponto de partida da ação, então nada foi em vão: todas as partes se diferenciaram, tornaram-se mais vinculadas, permitindo que mais conexões pudessem ocorrer entre variados fenômenos, ao engajar o destino de umas poucas entidades na vida e no destino de muitas outras, como nos sugere Latour (2002b).

As oficinas também funcionaram como ponto de encontro onde as crianças falavam sobre suas vidas, sobre as relações com suas famílias, na escola, na comunidade, tornando-se mais interessantes e interessadas, uma vez que promoviam uma articulação com o outro, fazendo 
eco nos projetos de vida e nas motivações do seu grupo de pertença. Como principal efeito deste projeto, pudemos desenvolver a possibilidade de operar sob a égide de uma lógica mais inclusiva: ao invés de execrarmos as nossas sobras, temos a chance de conviver com elas, buscando traduzi-las de uma outra forma, responsabilizandonos pelo que produzimos. Esperamos que estes sejam alguns dos esforços que nos cabem empreender para a construção de um mundo comum.

\section{Notas}

1 Um coletivo é entendido aqui como uma associação de vários elementos, humanos e não humanos, cuja agência deixa traços, na composição de um mundo comum.

2 Segundo Latour (1994a; Latour, Schwartz \& Charvolin, 1998), somos produtos híbridos, misturas de natureza e cultura, materialidade e socialidade, humanos e não humanos, numa mescla que se tece em redes de elementos heterogêneos.

3 Segundo Latour, Schwartz e Charvolin, (1998), com inspiração no próprio Serres de quem Latour foi discípulo, não é lícita a divisão entre as ciências ditas da natureza, tomadas como exatas, e aquelas dedicadas às humanidades, tidas como ciências moles, uma vez que a elas se atribui o estudo do erro, do que não é exato. A ciência, qualquer que seja, é uma fabricação humana e, portanto, é uma humana ciência.

4 Os não humanos compõem os coletivos com os humanos, tendo a potencialidade de se revelarem actantes, ou seja, de exercerem ou sofrerem algum tipo de ação, participando de um processo.É tudo que, não sendo humano, joga a favor da construção da nossa humanidade.

5 Actanteé uma palavra originária da semiótica que, segundo Latour (1994b), "permite ampliar a questão social a todos os seres que interagem numa associação e que intercambiam suas propriedades". (nota n. 24)

6 Recalcitrância é qualidade dos actantes cujas manifestações não são facilmente controladas, oferecendo resistências às tentativas de domesticação por parte de outros actantes.

7 Chamamos de sucatário a coleção do material de sucata, reunido e classificado para uso. A sucatoteca é outro termo utilizado para indicar o coletivo de sucata.

8 Ao iniciarem a transformação do material, sem uma idéia precisa do que teriam como resultado de seu trabalho, as crianças apelavam para esta denominação por conta das incertezas que cercavam o processo: quanto às suas próprias destrezas, quanto às recalcitrâncias do material, quanto às formas que iam se insinuando com as suas composições. Usando a palavra coisa, deixavam uma abertura para possíveis mudanças.

9 No sentido proposto por Latour (2002b), uma entidade significa tudo quanto existe ou pode existir.

10 Caixas pretas, segundo Latour, são "fatos inegáveis", "máquinas altamente sofisticadas", "teorias eficazes", "provas irrefutáveis", enfim, tudo aquilo que é dado como certo, pronto, usado por todos - "ponto de passagem obrigatória"-, cuja força e solidez apontam para uma grande quantidade de associações que mantêm coesa uma multidão de aliados, com a expectativa de operar bons efeitos (2000, p. 230)

11 Ver http://www.projetomegapet.com.br

12 MDF é a sigla utilizada para a expressão Médium Density Fibreboard, ou seja, tipo de prancha feita de fibras de madeira, colada a altas temperaturas e depois prensada, que tem sido apontada como uma opção mais ecológica para a madeira cujas reservas tendem a se esgotar no planeta, principalmente devido à exploração indiscriminada e a uma frágil política de reflorestamento, principalmente no caso brasileiro.

\section{Referências}

Bauer, M. (2003). Entrevista com Martin Bauer. Psicologia \& Sociedade, 15(1), 7-17.

Benjamin, W. (1984). Reflexões: A criança, o brinquedo, a educação. São Paulo, SP: Summus.

Cunha, N. H. S. (1988). Brinquedo, desafio e descoberta. Subsídios para utilização e confecção de brinquedos. Rio de Janeiro, RJ: FAE.

Didonet, V. (1982). O brinquedo feito pela criança. AMAE Educando, $48,15-17$.

Dosse, F. (2003). O império do sentido: A humanização das ciências humanas. Bauru, SP: EDUSC.

Latour, B. (1994a). Jamais fomos modernos. Rio de Janeiro, RJ: Editora 34.

Latour, B. (1994b). Une sociologie sans objet. Sociologie du Travail, 4, 587-607.

Latour, B. (1996). Do humano nas técnicas. In R. Scheps (Ed.) Império das técnicas (pp. 155-166). Campinas, SP: Papirus.

Latour, B. (2000). Ciência em ação: Como seguir cientistas e engenheiros sociedade afora. São Paulo, SP: Editora da Universidade Estadual de São Paulo.

Latour, B. (2001). A esperança de Pandora. Bauru, SP: EDUSC.

Latour, B. (2002a). The Promises of Constructivism. Retirado de http://www.ensmp.fr/ latour

Latour, B. (2002b). How to talk about the body? The normative dimension of sciences study. Retirado de http://www.ensmp.fr/ latour

Latour, B. (2003). Dialog on Actor Network Theory. Retirado de http://www.ensmp.fr/ latour

Latour, B., Schwartz, C., \& Charvolin, F. (1998). Crises nos meios ambientes: Desafios às ciências humanas. In H. R. Araújo (Ed.), Tecnociência e cultura. (pp. 91-125). São Paulo, SP: Estação Liberdade.

Latour, B. \& Woolgar, S. (1997). A vida de laboratório. A produção dos fatos científicos. Rio de Janeiro, RJ: Relume Dumará.

Law, J. (1997). Tradução/Traição-Notas sobre a Teoria Ator-Rede. Retirado de http://www.comp.lancs.ac.uk/sociology/papers

Law, J., \& Mol. A. M. (1995). Notes on materiality and sociality. The Sociological Review, 43(2), 274-294.

Machado, M. M. (1999). O brinquedo-sucata e a criança: A importância do brincar. Atividades e materiais. São Paulo, SP: Loyola. (Original publicado em 1994)

Serres, M. (1999). Luzes. Cinco entrevistas com Bruno Latour. São Paulo, SP: Unimarco.

Weiss, L. (1989). Brinquedos e engenhocas. São Paulo, SP: Scipione.

Maria de Fátima Aranha de Queiroz e Melo é Coordenadora do projeto, Professora do Departamento das Psicologias da Universidade Federal de São João del Rei (UFSJ), membro do Laboratório de Pesquisa e Intervenção Psicossocial (LAPIP) da UFSJ, Doutora do Programa de Pós-Graduação em Psicologia Social da Universidade Estadual do Rio de Janeiro (UERJ). 
Endereço para correspondência: Praça Dom Helvécio, 74, São João del Rei, MG, 36301-160. queirozmaldos@uaivip.com.br

Mônia Aparecida da Silva, Ellen Pinheiro Tenório de Albuquerque, Luciana Toledo de Melo Ramos, Dylene Elvira da Silva Gonçalves, Marcela Herthel de Oliveira e Gisele da Consolação Miranda são estagiárias do Projeto Sucata, alunas do Curso de Psicologia da UFSJ.

\section{Sucata vira brinquedo: tradução a partir de restos}

Maria de Fátima Aranha de Queiroz e Melo, Mônia Aparecida da Silva, Ellen Pinheiro Tenório de Albuquerque, Luciana Toledo de Melo Ramos, Dylene Elvira da Silva Gonçalves, Marcela Herthel de Oliveira e Gisele da Consolação Miranda Recebido: 11/09/2006

$1^{a}$ revisão: 20/03/2007

$2^{a}$ revisão: $24 / 04 / 2007$

Aceite final: 07/05/2007 